\title{
Underemployment of production factors in a forward-looking model*
}

\author{
David de la Croix ${ }^{\mathrm{a}, \mathrm{b},}$ *, Jean-François Fagnart ${ }^{\mathrm{b}}$ \\ ${ }^{a}$ National Fund for Scientific Research, Belgium \\ ${ }^{\mathrm{b}}$ University of Louvain, IRES, Place Montesquieu 3, B-1348 Louvain-la-Neuve, Belgium \\ Received November 1993; final version received November 1994
}

\begin{abstract}
This paper proposes a dynamic efficient bargaining model with a putty-clay technology and aggregation over heterogeneous micro markets. We analyse the agents' optimal response to unexpected real changes in their economic environment. The model gives a useful description of the linkages between unemployment and the rate of utilisation of productive equipment.
\end{abstract}

Keywords: Unemployment; Investment; Quantity constraints; Dynamic nonlinear model; Simulation

JEL classification: E22; E24; C68

\section{Introduction}

The persistence of unemployment at very high levels remains one of the most analysed stylised facts of the European economies. Although it is less often put forward by the literature, the underemployment phenomenon also concerns productive capital: as the business surveys indicate, most of the firms do not fully use their productive capacities and low utilisation rates are persistent. The link between the two underemployment phenomena has not been very extensively studied (an exception is the European Unemployment Programme as

\footnotetext{
* Corresponding author. David de la Croix gratefully acknowledges the financial support of the programme on Interuniversity Poles of attraction of the Belgian State (Prime Minister)
} 


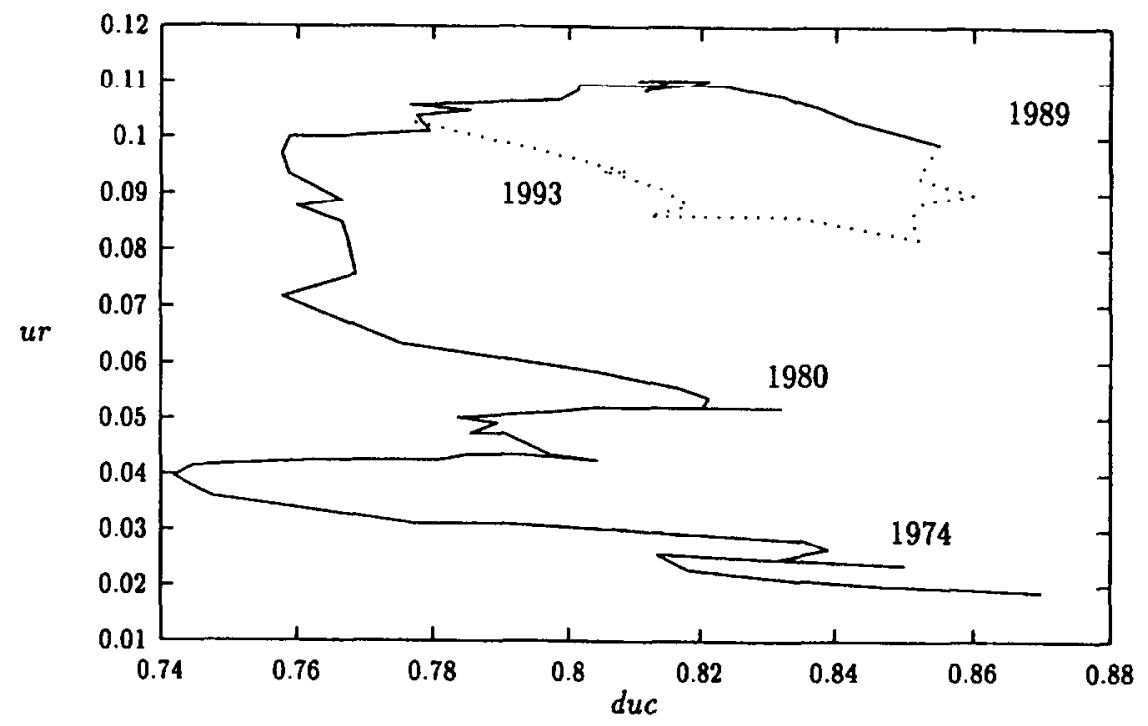

Fig. 1. Underutilisation of productive factors in the EEC.

reported in Drèze and Bean (1990)). The present paper aims at extending the analysis of the underemployment of capital and labour, by considering the dynamic relationship between unemployment (henceforth $u r$ ) and capacity utilisation (henceforth $d u c$ ). The interest of this analysis seems twofold. First, it should allow a better understanding of the empirical relationship between the two variables (see our comments on Fig. 1 below). Secondly, accounting for the link between $u r$ and $d u c$ should highlight the conditions under which an economy can create enough work-stations to ensure full employment.

Fig. 1 describes the relation between $u r$ and $d u c$ in the EEC. Although this relation exhibits some regularities, it is, however, non-monotonic. In particular, a negative correlation between the two variables exists at the beginning of each business cycle but there seems to be no clear covariance in the long run. For instance, in 1989 the rate of capital utilisation is the same as in 1974 but the unemployment rate is about six times higher. In other words, the behavior of $d u c$ appears much more cyclical than the behavior of $u r$. This suggests that over the last twenty years, there has been an increasing shortage of productive capacities with respect to the full-employment level (see e.g. Burda, 1986; Bean, 1989).

The quantity rationing models (hereafter $Q R M$ ) provide a natural framework for studying the behaviour of $u r$ and $d u c$. Using an explicit aggregation over heterogeneous micro markets, Sneessens (1987), Licandro (1992) and de la Croix (1993) show that imperfectly competitive wage and price settings combined with technological rigidities and market segmentation provide a convenient frame- 
work to study the underutilisation of the productive factors. Following these previous works, our paper is interested in the joint dynamics of $u r$ and $d u c$ in an intertemporal QRM model with imperfect competition. With respect to the dynamic bargaining models of Card (1986), Lockwood and Manning (1989) and Osano and Inoue (1991), the QRM framework stresses the role of productive capacities in determining employment.

The main features of the model are the following. The economy consists of segmented goods and labour markets in which the representative firm faces some uncertainty bearing on its demand and on the productivity of its factors. Due to this, the structural unemployment rate is positive and the average rate of capacity utilisation is lower than one. Introducing imperfectly competitive wage and price formation raises the unemployment rate above its structural level and may modify $d u c$. The dynamics of the model comes from the accumulation of productive capacities. In particular, each firm uses a putty-clay technology and the accumulation of productive units is made for expanding the production capacities of the firm and for implementing the technological change consecutive to changes in the relative prices of factors.

In the absence of nominal rigidities, the $u r$ and $d u c$ dynamics rely on real phenomena only. For this reason, our framework is not very far from the real business cycle methodology. Both try to explain macroeconomic stylised facts by the analysis of agents' optimal response to real shocks. Our framework focuses on the explanation of the underutilisation of productive factors which cannot be analysed with current RBC models, even when they allow for non-competitive wage formation as in Danthine and Donaldson (1989). Another interesting part of the QRM model is its nonlinear structure. Contrary to what $\mathrm{RBC}$ models do, we solve a numerical version of our model without linearising the trajectories towards the steady-state, using a technique proposed by Laffargue (1990) and Boucekkine (1995) for non-linear models with rational expectation. However, our model has some weaknesses with respect to RBC. In particular, the model is a partial equilibrium model with exogenous aggregate demand and interest rates.

The paper is organised as follows: the model is presented in Section 2 which devotes an important part to describe the productive technology (putty-clay). After having derived the microeconomic first-order conditions (Section 3), we present the aggregate dynamic model (Section 4) and analyse its steady state (Section 5). In Section 6, we propose numerical simulations describing the response of the model to unexpected changes in the environment analogous to those experienced by European economies during the last twenty years (oil shock, increased uncertainty, higher real interest rates). The induced dynamics of the endogenous variables gives a good qualitative insight on the way they could have react to these perturbations. In a last section (7) we discuss some important assumptions and properties of the model and indicate possible extensions. 


\section{The model}

\subsection{Technological choices and definition of productive capacities}

It is not possible to talk about a 'rate of capacity utilisation' without defining an upper limit to the productive capacity of the firm. Of course, some short-run technical rigidities are necessary to make this concept meaningful. When installing such or such productive equipment, a firm invests simultaneously in capital goods and in some technology. If ex ante it can freely choose them among the available ones, the decision of a couple capital stock-technology seems irreversible to a large extent: in most cases, modifying the technical coefficients of the productive factors will suppose new investments. In the literature, two approaches deal with this idea of a putty-clay technology accounting for short-run technological rigidities. The most sophisticated one is undoubtedly associated to the vintage models of capital. Unfortunately, this approach supposes to remember all the past of the investment process, which seems too cumbersome. The literature on adjustment costs may provide another explanation for technical rigidities: if the firm bears some cost to modify its capital-labour ratio, it will only invest in technological change progressively ${ }^{1}$ and the adjustment process will be spread optimally through time. As capital remains an homogeneous good, the overall investment process of the firm up to time $t$ is perfectly summarised by the capital stock and the capital-labour ratio at time $t$. However, a differentiable adjustment cost function is at best a reduced form of some unexplained microeconomic behaviour. ${ }^{2}$ In this paper, we try to capture the basic idea of a capital vintage model without supporting its prohibitive cost. We assume that firms accumulate productive capacities instead of capital goods.

Time is divided into an infinite number of discrete periods. Each period corresponds to the time necessary to build a new capacity. At time $t$, when a firm $h$ buys $i_{l}^{h}$ units of capital goods, it uses them to increase its productive capacity by $\Delta y c_{t}^{h}$. We suppose that these new installations are designed by combining $i_{t}^{h}$ and additional work-stations $\Delta n_{t}^{h}$ along a CES technology with constant return to scale:

$$
\Delta y c_{t}^{h}=\left[d\left(\Delta n_{t}^{h}\right)^{(\sigma-1) / \sigma}+(1-d)\left(i_{t}^{h}\right)^{(\sigma-1) / \sigma}\right]^{\sigma /(\sigma-1)},
$$

where $\sigma$ is the elasticity of substitution between capital and labour and $d$ is the parameter which weights the two factors. On top of $i_{t}^{h}$, the firm $h$ has thus to

\footnotetext{
1 This supposes that the adjustment cost function is differentiable.

${ }^{2}$ Furthermore, it is not clear whether capital units could incorporate technical progresses that are posterior to their installation even if some adjustment cost is paid.
} 
choose technical coefficients of labour $a_{t}^{h *}$ and equipment $b_{t}^{h^{* *}}$ :

$$
\left\{\begin{array}{l}
b_{t}^{h_{*}}=\left[\frac{\Delta y c_{t}^{h}}{i_{t}^{h}}\right]^{*}=\left[d\left(x_{t}^{h}\right)^{(\sigma-1) / \sigma}+(1-d)\right]^{\sigma /(\sigma-1)}, \\
a_{t}^{h_{*}}=\left[\frac{\Delta y c_{t}^{h}}{\Delta n_{t}^{h}}\right]^{*}=\left[d+(1-d)\left(x_{t}^{h}\right)^{-(\sigma-1) / \sigma}\right]^{\sigma /(\sigma-1)},
\end{array}\right.
$$

where $x_{t}^{h}$ is the labour-capital ratio embedded in the new equipment $\Delta n_{t}^{h} / i_{t}^{h}$. It is clear that $a_{t}^{h_{*}}=b_{t}^{h_{*}} / x_{t}^{h}$. These new production units are added to the old one $y c_{t-1}^{h}$ net of depreciation

$$
y c_{1}^{h}=y c_{t-1}^{h}(1-\delta)+\Delta y c_{t}^{h},
$$

where $\delta$ is the average depreciation rate.

This accumulation equation is clearly a simplification with respect to capital vintage models. Here, the firm will use all these productive capacities with the same intensity (i.e. at a mean rate of utilisation) instead of using first the most profitable units.

Since installing new capacities takes one period, the contemporary investment $\Delta y c_{t}^{h}$ becomes productive in $t+1$. The full capacity output at time $t$ is then given by

$$
y p_{t}^{h}=\tau y c_{t-1}^{h} v_{1 t}^{h},
$$

where $\tau$ is a productivity parameter which can be interpreted as the total factor productivity. $v_{1 t}^{h}$ is a i.i.d. random shock reflecting for instance the rate of technological breakdowns around a unitary mean. Hence, $E_{s}\left(y p_{t}^{h}\right)=\tau y c_{t-1}^{h}$.

When acquiring $\Delta y c_{t}^{h}$ production units, the firm creates a number of additional work-stations $\Delta n_{1}^{h}$ given by

$$
\Delta n_{t}^{h}=\frac{\Delta y c_{t}^{h}}{a_{t}^{h_{*}}}=x_{t}^{h} i_{t}^{h} .
$$

The total number of work-stations in the firm is

$$
n_{t}^{h}=\frac{y c_{t}^{h}}{a_{t}^{h}}
$$

where $a_{t}^{h}$ is the average technical productivity of labour. This identity allows to compute the evolution of $a_{t}^{h}$ :

$$
\frac{y c_{t}^{h}}{a_{t}^{h}}=\frac{y c_{t-1}^{h}}{a_{t-1}^{h}}(1-\delta)+x_{t}^{h} i_{t}^{h} .
$$

If the labour market is segmented, the firm has an upper limit on its employment given by the number of workers in its segment of the labour market $l s_{t}^{h}$. It is then possible to define a level of output corresponding to full employment,

$$
y s_{t}^{h}=\tau a_{t-1}^{h} l s_{t}^{h} v_{2 t}^{h}
$$


where $v_{2 t}^{h}$ is a i.i.d random shock of mean one representing the uncertainty on $l s^{h}$. The relevant technical coefficient is $a_{t-1}^{h}$ since the new work-stations in $t$ will only be productive in $t+1$. In expected terms, $E_{s}\left(y s_{t}^{h}\right)=\tau a_{t-1}^{h} l s_{t}^{h}$.

\subsection{Demand}

The utility function of the representative household is defined over a basket of imperfectly substitutable goods. The elasticity of substitution between the different goods; $\varepsilon$, is assumed constant and larger than one. The demand function for each good $h$ at time $t, y d_{t}^{h}$, is a share of total real demand $\bar{C}_{t} / p_{t}$ depending upon the ratio of the good's price $p_{t}^{h}$ to the general price index $p_{t}$ and upon a goodspecific random shock $\eta_{t}^{h}$, reflecting the uncertainty on the firm's market share:

$$
y d_{t}^{h}=\left(\frac{p_{t}^{h}}{p_{t}}\right)^{-\varepsilon} \frac{\bar{C}_{t}}{p_{t}} \eta_{t}^{h}, \quad \varepsilon>1 .
$$

The random shock $\eta_{t}^{h}$ is i.i.d. of mean 1 so that $\left.E_{s}\left(y d_{t}^{h}\right)=\left(p_{t}^{h} / p_{t}\right)\right)^{-\varepsilon} \tilde{C}_{t} / p_{t}$.

\subsection{Expected output}

Each firm $h$ has to announce its price $p_{t}^{h}$ in order to know its demand. After this price setting the firm observes its demand and its technological shocks occurring in the production process. ${ }^{3}$ Given the technical rigidities (putty-clay production function, one period time to build, fixed labour supply and segmented labour market), the firm can be constrained after the realisation of the shocks either by demand either by its productive capacity or by labour availability. Output is then the minimum of the three potential constraints:

$$
y_{t}^{h}=\min \left(y d_{t}^{h}, y s_{t}^{h}, y p_{t}^{h}\right) .
$$

As there is no labour hoarding in the model, the effective employment level is decided after the realisation of the shocks and is given by

$$
l_{t}^{h}=\frac{y_{t}^{h}}{\tau a_{t-1}^{h}} .
$$

If the shocks $\eta_{t}^{h}, v_{1 t}^{h}$ and $v_{2 t}^{h}$ are i.i.d. and lognormally distributed with a variance-covariance matrix with identical variances and identical covariances ${ }^{4}$, the expected output (before the realisation of the shocks) can be written as a CES

\footnotetext{
${ }^{3}$ The idea that prices are set before the complete revelation of demand is common to a lot of models, see e.g. Lucas and Woodford (1993).

${ }^{4}$ This particular hypothesis on the variance-covariance matrix is made for analytical simplicity. More general cases are possible but lead to less tractable functional forms for expected output. See e.g. Entorf et al. (1991).
} 
function of the three expected constraints (Lambert's (1988) theorem adapted by Sneessens (1983) to a three-constraint casc),

$$
E_{\mathrm{s}}\left(y_{t}^{h}\right)=\left[\left(E_{\mathrm{s}}\left(y d_{t}^{h}\right)\right)^{-\varrho}+\left(E_{s}\left(y s_{t}^{h}\right)\right)^{-\varrho}+\left(E_{\mathrm{s}}\left(y p_{t}^{h}\right)\right)^{-\varrho}\right]^{-1 / \ell},
$$

where $\varrho$ is a function of the variances and covariances of the shocks.

The interest of this formulation is twofold; first, following Lambert and Mulkay (1987), the ex ante probabilities of each constraint $y d, y p$ or $y s$ are

$$
\left\{\begin{array}{l}
\varphi_{D t}^{h}=\operatorname{Prob}\left(y d_{t}^{h}<\min \left[y p_{t}^{h}, y s_{t}^{h}\right]\right)=\left[\frac{E_{s}\left(y_{t}^{h}\right)}{E_{s}\left(y d_{t}^{h}\right)}\right]^{e+1} \\
\varphi_{P t}^{h}=\operatorname{Prob}\left(y p_{t}^{h}<\min \left[y d_{t}^{h}, y s_{t}^{h}\right]\right)=\left[\frac{E_{s}\left(y_{t}^{h}\right)}{E_{s}\left(y p_{t}^{h}\right)}\right]^{e+1} \\
\varphi_{L t}^{h}=\operatorname{Prob}\left(y s_{t}^{h}<\min \left[y p_{t}^{h}, y d_{t}^{h}\right]\right)=\left[\frac{E_{s}\left(y_{t}^{h}\right)}{E_{s}\left(y s_{t}^{h}\right)}\right]^{e+1}
\end{array}\right.
$$

Note that these probabilities do not add up to one because they do not cover the cases in which two out of the three constraints are equal and binding.

The elasticities of expected output to each expected constraint (denoted $\pi_{D t}^{h}$, $\pi_{P t}^{h}$ and $\pi_{L t}^{h}$ ) are increasing function of these probabilities

$$
\left\{\begin{array}{l}
\pi_{D t}^{h}=\eta_{E_{s}\left(y_{t}^{h}\right) \cdot E_{t}\left(y d_{t}^{h}\right)}=\left[\frac{E_{s}\left(y_{t}^{h}\right)}{E_{s}\left(y d_{t}^{h}\right)}\right]^{e}, \\
\pi_{P t}^{h}=\eta_{E_{s}\left(y_{t}^{h}\right) \cdot E_{t}\left(y p_{t}^{h}\right)}=\left[\frac{E_{s}\left(y_{t}^{h}\right)}{E_{s}\left(y p_{t}^{h}\right)}\right]^{e}, \\
\pi_{L t}^{h}=\eta_{E_{s}\left(y_{t}^{h}\right) \cdot E_{t}\left(y s_{t}^{h}\right)}=\left[\frac{E_{s}\left(y_{t}^{h}\right)}{E_{s}\left(y s_{t}^{h}\right)}\right]^{e} .
\end{array}\right.
$$

These elasticities, also called weighted probabilities by Lambert (1988), sum to 1:

$$
\eta_{E_{s}\left(y_{t}^{h}\right) \cdot E_{r}\left(y d_{t}^{h}\right)}+\eta_{E_{s}\left(y_{t}^{h}\right) \cdot E_{t}\left(y p_{t}^{h}\right)}+\eta_{E_{s}\left(y_{t}^{h}\right) \cdot E_{t}\left(y s_{t}^{h}\right)}=1 .
$$

Moreover, if the number of firms is sufficiently large, Sneessens (1987) proposes an interesting way to link the microcconomic problem to the macroeconomic aggregates detailed in the following subsection (see also Arnsperger and de la Croix (1993)).

\subsection{Aggregate output}

If the number of firms is large, aggregate output is equal to each firm's expected output times the number of firms. In that case, the ex post proportions of firms in each regime $\pi_{D}, \pi_{P}$ and $\pi_{L}$ are equal to the above ex ante individual 
elasticities and can be related to the unemployment rate, $u r_{t}=1-l_{t} / s_{t}$ and the degree of capacity utilisation $d u c_{t}=y_{t} / \tau y c_{t-1}$ :

$$
\begin{aligned}
& d u c_{t}=\left(\pi_{P_{t}}\right)^{1 / e} \\
& u r_{t}=1-\left(\pi_{L_{t}}\right)^{1 / e}=1-\left(1-\pi_{D_{t}}-\pi_{P_{t}}\right)^{1 / e}
\end{aligned}
$$

\subsection{Unions}

Each union is firm-specific and composed of the $l s_{t}{ }^{h}$ households which supply their work to firm $h$. As in Card (1986), the union's utility function is defined over employment $l_{t}^{h}$ and over the difference between the real wage $w_{t}^{h} / p_{t}$ and the disutility of work $\bar{u}_{t}$ (the alternative wage in Card's model):

$$
U\left(l_{t}^{h}, \frac{w_{t}^{h}}{p_{t}}\right)=l_{t}^{h} \frac{1}{v}\left(\frac{w_{t}^{h}}{p_{t}}-\bar{u}_{t}\right)^{v} .
$$

The parameter $v$ can be interpreted as a relative preference for wages with respect to employment. It measures the concavity of the utility function with respect to the wage net of the disutility of work; in the presence of uncertainty, $1-v$ is the coefficient of relative risk aversion of the union, with $v=1$ implying risk neutrality.

\subsection{Efficient bargaining}

The union and the firm bargain ex-ante in a cooperative way (this assumption of efficient contract is discussed in the last section). An agreement is concluded without knowing the realisation of demand and productivity shocks and bears both on wages and on expected employment. ${ }^{5}$ In our setting, a negotiation over expected employment will determine simultaneously the price, the investment level and the technical coefficients. Since the two agents have the same discount rate, it is equivalent ${ }^{6}$ to negotiate at each point in time over $p_{t}{ }^{h}, w_{t}{ }^{h}, x_{t}{ }^{h}$ and $i_{t}{ }^{h}$ or to determine once for all the complete path of these variables. This would of course be no longer true if the idiosyncratic random shocks were not i.i.d. since then the history of shocks would affect future decisions.

The objective function is the weighted sum of all future utilities and profits: since output and effective employment are decided afterwards, they must be

\footnotetext{
${ }^{5}$ At the firm lcvel, the expected employment is equal to the number of work-stations in the firm times their probability of utilisation.

${ }^{6}$ This supposes of course that there is no unexpected change in the exogenous variables.
} 
expressed in expected terms at the time of bargaining.

$$
\max _{w_{t}^{h}, p_{t}^{h}, i_{t}^{h}, x_{t}^{h}} E_{s}\left[\beta \sum_{t=s}^{\infty} \vartheta_{t} U_{t}\left(l_{t}^{h}, \frac{w_{t}^{h}}{p_{t}}\right)+\sum_{t=s}^{\infty} \vartheta_{t} \frac{1}{p_{t}}\left(p_{t}^{h} y_{t}^{h}-w_{t}^{h} l_{t}^{h}-p_{t}^{i} i_{t}^{h}\right)\right]
$$

such that for all $t$

$$
\begin{aligned}
& y c_{t}^{h}=y c_{t-1}^{h}(1-\delta)+\Delta y c_{t}^{h}, \\
& \frac{y c_{t}^{h}}{a_{t}^{h}}=\frac{y c_{t-1}^{h}}{a_{t-1}^{h}}(1-\delta)+x_{t}^{h} i_{t}^{h}, \\
& i_{t}^{h} \geq 0
\end{aligned}
$$

and where $l_{t}^{h}, i_{t}^{h}, y_{t}^{h}, y c_{t}^{h}$ and $x_{t}^{h}$ have been defined before. The parameter $\beta$ which weights the agents' objective function represents the union's relative power in the bargaining process. $\vartheta_{t}$ is a discounting factor given by

$$
\vartheta_{t}=\prod_{j=s}^{t}\left(\frac{1}{1+r_{j}}\right)
$$

where $r_{j}$ is the union's time-preference parameter and the firm's discount rate.

Note finally that our bargaining framework is only efficient in 'expected terms' since there is no agreement on the effective employment level. In order to ensure non-negative profits, the firm has indeed to keep one degree of freedom in choosing optimally effective employment after the shocks. ${ }^{7}$ However, the ex ante decisions about prices and technology are more favourable to employment than what they would have been if the negotiation had only born on wages.

Associating Lagrange's multipliers to the different constraints, one could recast the bargaining problem in the following way:

$$
\begin{aligned}
& \max _{w_{t}^{h}, p_{t}^{h}, i_{t}^{h}, x_{t}^{h}} \beta \sum_{t=s}^{\infty} \vartheta_{t} E_{s}\left(l_{t}^{h}\right) \frac{1}{v}\left(\frac{w_{t}^{h}}{p_{t}}-\bar{u}_{t}\right)^{v} \\
& \left.+\sum_{t=s}^{\infty} \vartheta_{t} \frac{1}{p_{t}}\left[\left(p_{t}^{h}-\frac{w_{t}^{h}}{\tau a_{t-1}^{h}}\right) E_{s}\left(y_{t}^{h}\right)-p_{t}^{i} i_{t}^{h}\right)\right] \\
& +\sum_{t=s}^{\infty} \vartheta_{t} \lambda_{t}\left[y c_{t}^{h}-y c_{t-1}^{h}(1-\delta)-b_{i}^{h} i_{t}^{h}\right] \\
& +\sum_{t=s}^{\infty} \vartheta_{t} \mu_{t}\left[\frac{y c_{t}^{h}}{a_{t}^{h}}-\frac{y c_{t-1}^{h}}{a_{t-1}^{h}}(1-\delta)-x_{t}^{h} i_{t}^{h}\right] \\
& +\sum_{t=s}^{\infty} \vartheta_{t} \gamma_{t} i_{t}^{h} .
\end{aligned}
$$

\footnotetext{
${ }^{7}$ That means that the effective rate of occupation of the existing work-stations is decided ex post.
} 


\section{First-order conditions}

\subsection{Optimal pricing}

The first-order condition for price is

$$
p_{t}^{h}=\left[1-\frac{1}{\varepsilon \pi_{D t}^{h}}\right]^{-1} \frac{\tilde{w}_{t}}{\tau a_{t-1}^{h}},
$$

where

$$
\tilde{w}_{t}=\left[w_{t}^{h}-\frac{\beta}{v}\left(\frac{w_{t}^{h}}{p_{t}}-\bar{u}\right)^{v} p_{t}\right] .
$$

The term $\tilde{w}_{t}$ represents the marginal labour cost corrected for the effect of the efficient nature of the bargain: the price formation internalises the positive effect of employment on the union's utility level.

According to this price equation, the price is a mark-up over the 'social' marginal cost of labour. The mark-up rate depends positively on the firm market power and negatively on union power. Moreover, it decreases with the endogenous probability of facing a demand constraint. Since, in (20), the gap between the social marginal cost of labour and the private $\operatorname{cost} w_{t}$ is a function of union power $\beta$, the mark-up rate of prices over money wages is a negative function of $\beta$.

\subsection{Optimal real wage}

The first-order equation for wages is

$$
\frac{w_{t}{ }^{h}}{p_{t}}=(\beta)^{1 /(1-\nu)}+\bar{u} .
$$

Real wages are equal to the disutility of work plus a positive term positively related to the union power. This equation is comparable to the usual result of bargaining models where the wage is a mark-up over the fall-back position of the union or over its 'outside wage'.

\subsection{Investment and technological choices}

Let us write the real social marginal surplus per unit of output $S_{t}^{h}$ as

$$
S_{t}^{h}=\frac{1}{p_{t}}\left(p_{t}^{h}-\frac{\tilde{w}_{t}}{\tau a_{t-1}^{h}}\right) .
$$

The first-order condition for $i_{t}^{h}$ is

$$
\gamma_{t}=\frac{p_{t}^{i}}{p_{t}}+\lambda_{t}^{h} b_{t}^{h_{*}}+\mu_{t}^{h} x_{t}
$$


For $x_{t}^{h}$

$$
\lambda_{t}^{h}+\frac{1}{d}\left[\frac{x_{t}^{h}}{b_{t}^{h *}}\right]^{1 / \sigma} \mu_{t}^{h}=0
$$

The Slatter's condition for the positivity of investment is

$$
\gamma_{t}^{h} i_{t}^{h}=0
$$

The optimality condition for $y c_{t}^{h}$ is

$$
\left(1+r_{t}\right)\left(\lambda_{t}^{h}+\frac{\mu_{t}^{h}}{a_{t}^{h}}\right)-(1-\delta)\left(\lambda_{t+1}^{h}+\frac{\mu_{t+1}^{h}}{a_{t}^{h}}\right)+\tau \varphi_{P t+1}^{h} S_{t+1}=0,
$$

and for $a_{t}^{h}$,

$$
y c_{t}^{h}\left[\left(1+r_{t}\right) \frac{\mu_{t}^{h}}{a_{t}^{h}}-(1-\delta) \frac{\mu_{t+1}}{a_{t}^{h}}\right]=S_{t+1}^{h} \varphi_{L t+1}^{h} \tau a_{t}^{h} l s_{t+1}^{h}+\frac{\tilde{w}_{t+1}}{p_{t+1}} \frac{E_{t}\left(y_{t+1}^{h}\right)}{\tau a_{t}^{h}} .
$$

This set of optimality conditions on investment and technology is not really 'reader friendly'. The economic interpretation is eased if we rewrite these conditions as three equations on $y c_{t}^{h}, x_{t}$ and $\mu_{t}^{h}$ (plus the Slatter's condition). The reader's understanding will not be altered substantially if he limits his reading to the intuitive comments proposed after each equation. These comments should give enough elements to understand the determinants of investment and technical choices. The more detailed analysis of the determination of the equilibrium at the steady state will give further insights on the working of the model.

(a) The condition on $y c_{t}^{h}$ can be rewritten as

$$
\begin{aligned}
& \frac{\left(1+r_{t}\right)}{b_{t}^{h_{*}}}\left(\frac{p_{t}^{i}}{p_{t}}-\gamma_{t}^{h}\right)=\frac{1-\delta}{b_{t+1}^{h_{*}}}\left(\frac{p_{t+1}^{i}}{p_{t+1}}-\gamma_{t+1}^{h}\right)+\left(1+r_{t}\right) \mu_{t}^{h}\left(\frac{1}{a_{t+1}^{h_{*}}}-\frac{1}{a_{t}^{h_{*}}}\right) \\
& +\tau S_{t+1}^{h} \varphi_{P t+1}^{h}+\left\{S_{t+1}^{h} \varphi_{L t+1}^{h} \tau a_{t}^{h} l s_{t+1}^{h}+\frac{\tilde{w}_{t+1}}{p_{t+1}} \frac{E_{t}\left(y_{t+1}^{h}\right)}{\tau a_{t}^{h}}\right\} \\
& \quad \times \frac{1}{y c_{t}^{h}}\left(1-\frac{a_{t}^{h}}{a_{t+1}^{h *}}\right) .
\end{aligned}
$$

This optimality condition on $y c_{t}^{h}$ is to understand as follows. Let us first suppose that investment is strictly positive. The terms in $\gamma_{t}$ and $\gamma_{1+1}$ vanish. As long as the firm doesn't change the nature of its technology, the technical coefficients remain constant and $a_{t+1}^{*}=a_{t}^{*}=a_{t}$. The condition on $y c_{t}^{h}$ becomes simply:

$$
\left(1+r_{t}\right) \frac{p_{t}^{i}}{p_{t}} \frac{1}{\tau b_{t}^{h_{*}}}-\frac{p_{t+1}^{i}}{p_{t+1}} \frac{1-\delta}{\tau b_{t+1}^{h_{*}}}=S_{t+1}^{h} \varphi_{P t+1}^{h}
$$


The left-hand side represents the net cost in $t$ of installing one unit of productive capacity (i.e. purchasing $1 /\left(\tau b_{t}^{*}\right)$ capital goods at a price $p_{t}^{i}$ and bearing the cost of its depreciation). Optimally, this net marginal cost must be equal to the expected marginal revenue generated by this capacity unit in $t+1$ : this one corresponds to the extra social marginal revenue $S_{t+1}^{h}$ times the probability of using this new capacity unit $\varphi_{P t+1}$.

When the firm decides to modify the labour intensity of its production, investing in new capacity units is the only way to implement the required technical change. In this case, other terms come naturally in the optimality condition for $y c_{r}^{h}$.

First, when changing the technical productivity of labour, the firm modifies the level of production corresponding to the full employment output. If $a_{t}^{h}$ is increased (resp. decreased), this technical change will cause a gain (resp. a loss) in operating surplus if the employment constraint becomes binding. In expected terms, this marginal variation in operating surplus has to be multiplied by the probability of a labour constraint $\varphi_{L}$. This justifies the presence of the following expression in the second line of the condition on $y c_{t}^{h}$ :

$$
S_{t+1}^{h} \varphi_{L t+1}^{h} \frac{\tau l s_{t+1}^{h} a_{t}^{h}}{y c_{t}^{h}}
$$

Secondly, at given output, the change in technical productivity of labour will affect the average wage cost of a workplace. If $a_{t}$ is increased, the induced economy in wage bill is measured by

$$
\frac{\tilde{w}_{t+1}}{\tau a_{t}^{h}} \frac{E_{t}\left(y_{t+1}^{h}\right)}{y c_{t}^{h}} .
$$

(b) The optimality condition for the labour-capital ratio can be rewritten as

$$
\begin{aligned}
& \tau S_{t+1}^{h}\left\{\varphi_{P t+1}^{h}-\varphi_{L t+1}^{h}\left(\frac{a_{t}^{h}}{d a_{t+1}^{h * 1 / \sigma}}-1\right) \frac{l s_{t+1}^{h} a_{t}^{h}}{y c_{t}^{h}}\right\} \\
& -\frac{1}{p_{t+1}} \frac{\tilde{w}_{t+1}}{\tau a_{t}^{h}} \frac{E_{t}\left(y_{t+1}^{h}\right)}{y c_{t}^{h}}\left(\frac{a_{t}^{h}}{d a_{t+1}^{* 1 / \sigma}}-1\right)+\frac{\left(1+r_{t}\right) \mu_{t}^{h}}{d}\left(a_{t+1}^{*-1 / \sigma}-a_{t}^{*-1 / \sigma}\right)=0 .
\end{aligned}
$$

The firm chooses its labour-capital ratio in such a way that the expected marginal revenue of the increase in this ratio (line 1) is equal to the extra wage bill (line 2) due to the lower labour productivity. The expected marginal revenue is in fact a comparison between a higher operating surplus due to a higher productivity of capital goods in the case $\varphi_{P}$ of a capacity constraint and a lower one due to a lower productivity of labour in the case $\varphi_{L}$ of a labour constraint. 
(c) Finally, using (22), (23) and (26), we have the law of motion of $\mu_{t}^{\text {h.8 }}$

$$
\frac{y c_{t}^{h}}{a_{t}^{h}}\left(\left(1+r_{t}\right) \mu_{t}^{h}-(1-\delta) \mu_{t+1}^{h}\right)=S_{t+1}^{h} \varphi_{L t+1}^{h} \tau a_{t}^{h} s_{t+1}^{h}+\frac{\tilde{w}_{t+1}}{p_{t+1}} \frac{E_{t}\left(y_{t+1}^{h}\right)}{\tau a_{t}^{h}} .
$$

\section{Aggregation}

At the symmetric Nash equilibrium between the different 'union-firm' couples, the aggregation is particularly simple: since all agents are in the same situation at the time of bargaining, they choose the same wages, prices and the same technology. Consequently, the aggregate price level is

$$
p_{t}=p_{t}^{h}=p_{t}^{i} .
$$

Furthermore, if the number of firms is large, the aggregate output is equal (up to a scaling factor) to the expected output of each firm:

$$
y_{t}=\left[\left(y d_{t}\right)^{-\varrho}+\left(\tau y c_{t-1}\right)^{-\varrho}+\left(\tau a_{t-1} l s_{t}\right)^{-\varrho}\right]^{-1 / \varrho},
$$

with

$$
y d_{t}=\frac{\bar{C}_{t}}{p_{t}}
$$

Removing the superscript $h$ in marginal conditions given earlier, we may then rewrite the whole model in terms of aggregate variables. As there is no aggregate uncertainty, the expectation operator can be removed. Note furthermore that the social operating surplus per unit of output can be simply recasted: indeed, using (19), we have that

$$
S_{t}=1-\frac{\tilde{w}_{t} / p_{t}}{\tau a_{t-1}}=\frac{1}{\varepsilon \pi_{D_{t}}} .
$$

The aggregate dynamic model is then given by:

${ }^{8}$ Denoting the number of work-stations $y c_{t}^{h} / a_{t}^{h}$ at $t$ by $n_{t}^{h}$ and substituting recursively $\mu_{t+i}^{h}$ by its value in terms of variables of the subsequent period $t+i+1, \mu_{t}^{h}$ can be expressed as

$$
\mu_{t}^{h}=\sum_{j=t+1}^{\infty} \frac{(1-\delta)^{j-t-1}}{\prod_{s=t+1}^{x}\left(1+r_{s}\right)}\left[S_{j}^{h} \pi_{L_{j}}^{h}+\frac{\tilde{w}_{j} / p_{j}}{\tau a_{j-1}^{h}}\right] E_{s}\left(y_{j}^{h}\right) / n_{j}^{h} .
$$

$\mu_{t}$ is thus a measure of the discounted sum per workplace of the effect of an increase in the productivity of labour in $t$ on expected future revenues. 
(A) technical coefficients and accumulation equations

$$
\left\{\begin{array}{l}
b_{t}^{*}=\left[d\left(x_{t}\right)^{(\sigma-1) / \sigma}+(1-d)\right]^{\sigma /(\sigma-1)}, \\
a_{t}^{*}=b_{t}^{*} / x_{t}, \\
y c_{t}=y c_{t-1}(1-\delta)+b_{t}^{*} i_{t}, \\
y c_{t} / a_{t}=\left(y c_{t-1} / a_{t-1}\right)(1-\delta)+x_{t} i_{t},
\end{array}\right.
$$

(B) aggregate demand and output and related business cycle indicators

$$
\left\{\begin{array}{l}
y d_{t}=\frac{\bar{C}_{t}}{p_{t}} \\
y_{t}=\left[\left(y d_{t}\right)^{-\varrho}+\left(\tau y c_{t-1}\right)^{-\varrho}+\left(\tau a_{t-1} l s_{t}\right)^{-Q}\right]^{-1 / e} \\
d u c_{t}=\frac{y_{t}}{\tau y c_{t-1}} \\
\pi_{D t}=\left(\frac{y_{t}}{y d_{t}}\right)^{Q}
\end{array}\right.
$$

(C) price and wage formation

$$
\left\{\begin{array}{l}
1-\frac{1}{\varepsilon \pi_{D_{t}}}=\frac{w_{t} / p_{t}}{\tau a_{t-1}}-\frac{\beta}{v} \frac{1}{\tau a_{t-1}}\left(\frac{w_{t}}{p_{t}}-\bar{u}\right)^{v}, \\
\frac{w_{t}}{p_{t}}=\beta^{1 /(1-v)}+\bar{u}
\end{array}\right.
$$

(D) capacities, investment and labour-capital ratio

$$
\begin{aligned}
\left(1+r_{t+1}\right) \frac{1-\gamma_{t}}{\tau b_{t}^{*}}= & (1-\delta) \frac{1-\gamma_{t+1}}{\tau b_{t+1}^{*}}+\left(1+r_{t+1}\right)\left(\frac{\mu_{t}}{\tau a_{t+1}^{*}}-\frac{\mu_{t}}{\tau a_{t}^{*}}\right)+\frac{\left(d u c_{t+1}\right)^{\rho+1}}{\varepsilon \pi_{D_{t+1}}} \\
& +\left(1-\frac{1}{\varepsilon}-\frac{d u c_{t+1}^{Q}}{\varepsilon \pi_{D_{t+1}}}\right) d u c_{t+1}\left(1-\frac{a_{t}}{a_{t+1}^{*}}\right), \\
\gamma_{t} i_{t}=0 & \\
\frac{d u c_{t+1}^{Q+1}}{\varepsilon \pi_{D_{t+1}}}= & \left(1+r_{t+1}\right) \frac{\mu_{t}}{\tau d}\left(a_{t}^{*-1 / \sigma}-a_{t+1}^{*-1 / \sigma}\right) \\
& -\left(1-\frac{1}{\varepsilon}-\frac{d u c_{t+1}^{Q+1}}{\varepsilon \pi_{D_{t+1}}}\right) d u c_{t+1}\left(1-\frac{a_{t}}{d a_{t+1}^{* 1 / \sigma}}\right), \\
\left(1+r_{t+1}\right) \mu_{t} \frac{y c_{t}}{a_{t}}= & \mu_{t+1}(1-\delta) \frac{y c_{t}}{a_{t}}+\frac{\tau a_{t} l s_{t+1}}{\varepsilon \pi_{D_{t+1}}}\left[\frac{y_{t+1}}{y s_{t+1}}\right]^{\rho+1}+\left(1-\frac{1}{\varepsilon \pi_{D_{t+1}}}\right) y_{t+1} .
\end{aligned}
$$




\section{The steady state}

The steady state is characterised by the absence of both change in technical coefficients and net investment $(\gamma=0)$. In particular, the effective productivity of labour is equal to its optimal valuc: $a_{t}=a_{t}{ }^{*}=a^{*}$. The long-run level of productive capacities determines the stationary value of investment

$$
i=\delta \frac{y c}{b^{*}}
$$

Without the short-run dynamics duc to the accumulation and the technological change, the aggregate model becomes

$$
\begin{aligned}
& b^{*}=\left[d x^{(\sigma-1) / \sigma}+(1-d)\right]^{\sigma /(\sigma-1)}, \\
& a^{*}=b^{*} / x \\
& y d=\frac{\bar{C}}{p} \\
& y=\left[(y d)^{-\varrho}+(\tau y c)^{-\varrho}+\left(\tau l s a^{*}\right)^{-\varrho}\right]^{-1 / \varrho}, \\
& \pi_{D}=\left(\frac{y}{y d}\right)^{\varrho}, \\
& d u c=\frac{y}{\tau y c}, \\
& 1-\frac{1}{\varepsilon \pi_{D}}=\frac{w}{p \tau a^{*}}-\frac{\beta}{v} \frac{1}{\tau a^{*}}\left(\frac{w}{p}-\bar{u}\right)^{v}, \\
& \frac{w}{p}=\beta^{1 /(1-v)}+\bar{u}, \\
& r+\delta=d u c^{e^{-1}} 1 \frac{b^{*} \tau}{\varepsilon \pi_{D}}, \\
& 0=\frac{d u c^{\varrho}}{\varepsilon \pi_{D}}-\left[1-\frac{1}{\varepsilon}-\frac{d u c^{\varrho}}{\varepsilon \pi_{D}}\right] \frac{1-d}{d}(x)^{-(\sigma-1) / \sigma}
\end{aligned}
$$

Fquations (a) to (f) are definitions. Fquations (g) and (h) describe the price-wage block of the model. Equation (i) concerns productive capacities and can be recasted as

$$
\frac{r+\delta}{d u c}=\frac{b^{*} \tau}{\varepsilon \pi_{D}} d u c^{\varrho} .
$$


On the left-hand side, $r+\delta$ is the real user cost of productive equipment. As each unit of capital is used at a rate $d u c$, the true user cost of one unit of capital is $(r+\delta) / d u c$. This marginal cost must be equal to the expected marginal revenue given by the physical productivity of equipment $\tau b^{*}$ times the product of the social operating surplus per unit of output $1 /\left(\varepsilon \pi_{d}\right)$ and the elasticity of output to capacities $d u c^{e}$

Equation ( $\mathrm{j}$ ) is the long-run optimality condition on the labour-capital ratio $x$. Let us rewrite it in the following way:

$$
\frac{1}{\varepsilon \pi_{D}}\left(d u c^{\varrho}-\left[\frac{y}{\tau a^{*} l s}\right]^{e} \frac{1-d}{d} x^{(1-\sigma) / \sigma}\right)=\left(1-\frac{1}{\varepsilon \pi_{D}}\right) \frac{1-d}{d} x^{(1-\sigma) / \sigma} .
$$

When the labour-capital ratio is increased, the productivity of capital (resp. labour) rises (resp. diminishes). The net effect on output depends on the size of the elasticity of output to capacities $\left(d u c^{Q}\right)$ with respect to the elasticity of output to the labour constraint $\left((y /(\tau a l s))^{\rho}\right)$. The difference between the two which is measured for a unitary increase in capacities is multiplied by the social operating surplus $1 /\left(\varepsilon \pi_{D}\right)$. Furthermore, the lower labour productivity raises the unit labour cost $\left(1-\left(\varepsilon \pi_{D}\right)^{-1}\right)$ and thus the wage bill. The optimal $x$ is such that the two terms are equal.

The determination of the steady-state equilibrium obeys to the following sequence: The equations of prices and wages determine the proportion $\pi_{D}$ which is equal to

$$
\pi_{D}=\frac{1}{\varepsilon}\left[1-\frac{1}{\tau a^{*}}\left(\bar{u}+\beta^{1 /(1-v)}\left(1-\frac{1}{v}\right)\right)\right]^{-1} .
$$

Note that the relative importance of this demand constraint is not linked to a Keynesian phenomenon. Here, firms and unions choose voluntary the possibility of a demand constraint: given the prevailing uncertainty, their pricing policy gives them an optimal probability $\varphi_{D}$ to face insufficient demand. Thus, a proportion of firms $\pi_{D}$ reporting such a shortage is simply the macroeconomic implication of these microeconomic choices. This does not mean at all that an anticipated boom in nominal demand would produce a rise in output. Rather, firms would change their prices in order to keep the same optimal $\pi_{D}$.

This value of $\pi_{D}$ allows to write the long-run first-order conditions for the productive capacities and the technological choices as a system of two nonlinear equations with two unknowns $d u c$ and $x\left(b^{*}\right.$ and $a^{*}$ are monotonic functions of $x$ ):

$$
\left\{\begin{array}{l}
d u c=\left(\frac{\varepsilon \pi_{D}(r+\delta)}{\tau b^{*}}\right)^{1 /(\varrho+1)}, \\
x=\left(\frac{1-d}{d}\left[\frac{(\varepsilon-1) \pi_{D}}{d u c^{\varrho}}-1\right]\right)^{\sigma /(\sigma-1)} .
\end{array}\right.
$$


This system determines the equilibrium values of $d u c$ and $x$ and consequently $\pi_{D}$. Subsequent substitutions in the other equations allow to find the values of the remaining variables.

As mentioned in Section 2, $u r$ is fully determined by equilibrium $\pi_{D}$ and $d u c$ (i.e. $\pi_{P}$ as $\pi_{P}=d u c^{\text {) }}$ ) since

$$
u r=1-\left(1-\pi_{\mathrm{D}}-\mathrm{duc}^{\varrho}\right)^{1 / Q} \text {. }
$$

It is not possible to obtain closed-form solutions for $d u c, x$ (and thus $u r$ ). The most likely sign of some partial derivatives of these variables with respect to parameters of the model can, however, be clarified after further substitutions. The following table summarises the sign of the derivatives of $d u c, x$ and $u r$ with respect to the most important parameters:

$\begin{array}{lcccc} & d u c & \pi_{D} & u r \\ \text { interest rate } r & + & + & + & + \\ \text { competition } \varepsilon & - & 0 & + & - \\ \text { productivity } \tau & - & 0 & - & - \\ \text { micro uncertainty } 1 / \varrho & - & + & ? & + \\ \text { wage claim } \bar{u} & + & - & ? & +\end{array}$

\section{Dynamic analysis}

In spite of the smoothness of the equations of the model due to the aggregation over different 'minimum' conditions, the above QRM model remains non linear enough to wish to avoid a linearisation. For this reason we solve it numerically and verify the existence of a saddle point trajectory for the specific calibration that is presented in the next subsection. The resolution relies on a Newton-Raphson relaxation method which has been proposed by Laffargue (1990) for solving dynamic non-linear models with rational expectations. The general problem is to solve a system of finite difference equations with initial and terminal conditions. Approximating the infinite horizon by a finite one ${ }^{9}$, the complete system has got as many equations as the number of equations at each period times the simulation horizon plus the initial and terminal conditions. This system is then solved using a Newton-Raphson algorithm in which the improvement at each linearisation is computed thanks to a triangulation procedure. ${ }^{10}$

\footnotetext{
${ }^{9}$ That means that the transversality conditions on anticipated variables are replaced by the steady-state values of these variables at the end of the horizon of simulation.

${ }^{10}$ As the equations of the model at the different periods $t$ are concatenated horizontally, the matrix of the complete system has a block recursive form: indeed, the first non-zero elements in the rows representing the equations of the model at $t$ are to the right of those in the rows describing the system al time $t-1$ (the gap between the first non zero columns at $t-1$ and the one at $t$ is in fact given by the number of endogenous variables in the model). This interesting block structure is of course taken into account for implementing the triangulation procedure.
} 
Of course, as any rational expectations model, our model may have an infinity of solutions. It is generally accepted that this aspect is not crucial if only one of these solutions is stable. The preliminary step of the resolution is then to determine whether the model admits a saddle point path. Traditionally, this is done by computing the eigenvalues of the linearised model and checking whether they verify the Blanchard-Kahn (1980) conditions for the existence of a saddle point. As Boucekkine (1995) shows, this rigorous but cumbersome verification is unnecessary when Laffarguc's method is used. This algorithm is indeed characterised by an explosiveness property when the model has got an infinity of stable solutions (in fact, this property can be generalised to any convergent relaxation method, see Boucekkine and Le Van (1993)). The explosive behaviour can be revealed by a very simple numerical procedure relying on the initialisation of the relaxation. ${ }^{11}$ This procedure has allowed us to conclude unambiguously that a unique saddle point path exists, at least for our specific calibration.

\subsection{Calibration}

The calibration of the model has been done using information from the available econometric models in order to replicate the magnitude of Belgian aggregate data. The elasticity of substitution between capital and labour $\sigma$ has been put to 0.4 which is what is find in general when one estimates a CES function for Belgium or France. The coefficient of labour in the CES function $d$ has been put to 0.7 which should be equal to the labour share in added-value when $\sigma \rightarrow 1$. The depreciation rate $\delta$ linked to the capital stock series that we use is 0.04 . The real long-term interest rate $r$ on an annual basis is 0.08 . Labour supply $l s$ is 0.034 ( 3.4 millions). The global productivity of factors has been computed in order to retrieve the magnitude of Belgian GDP given the other parameters $(\tau=7.75)$.

The mismatch parameter $\varrho$ is estimated near 20 both by the Belgian Planning Bureau and by the estimates of presented in Drèze and Bean (1990). It is more arbitrary to choose the elasticity of substitution between goods $\varepsilon$ since we do not have reliable econometric estimates of it. Moreover, different calibrations have shown us that the model responses are particularly sensitive to the value of $\varepsilon$. We have chosen 5 , which means a mark-up rate of about $40 \%$ and a proportion of demand-constrained firms around $60 \%$. This last proportion is consistent with the survey of the National Bank of Belgium.

Concerning the parameters related to the union we have still quite less information. A reasonable value for $v$ seems to be 0.5 . The value of the parameter

\footnotetext{
${ }^{11}$ That procedure consists in initialising the relaxation with values of the variables that slightly differ from the steady state one. If the model admits an infinity of stable solutions, the explosive behaviour appears at the first Newton-Raphson improvement.
} 
related to the bargaining power of the union $\beta$ is not interpretable since it includes also a normalisation factor of the utility function of the union. $\beta$ has been set equal to 0.5 . Finally, given $v$ and $\beta$ the disutility of work $\bar{u}$ has been chosen to replicate the magnitude of real wage with respect to labour productivity. The induced long-run values for endogenous variables are: $\pi_{d}=0.62$, $d u c=0.91, x=0.285, y=0.298, i=0.0048, u r=0.07$.

\subsection{Simulation exercises}

We propose hereafter four simulation exercises. Three out of them concern unexpected changes in parameters of the model that are supposed to have occurred in European economies over these last twenty years, i.e.

- an increase in the real interest rate reflecting the tight monetary policies of the eighties;

- a negative change in the global productivity parameter $\tau$ which can be interpreted as an oil shock; ${ }^{12}$

- a decrease in $\varrho$ which expresses a larger uncertainty at the microeconomic level and an increase in the mismatch between aggregate demand and supply. In empirical works, this lower $\varrho$ appears as an aftermath of the first oil shock (see Drèze and Bean, 1990).

The last exercise concerns the appearance of a new technology augmenting the productivity of labour. Given the putty-clay nature of the production function, it can only be incorporated in the productive equipment through new investments.

All these changes are unanticipated but expected to be permanent once occurred.

It is useful to define the notion of capital gap $\mathrm{cg}$. It is the unemployment rate that would prevail if all the existing productive capacities were fully utilised. Thus,

$$
c g_{1}=1-\frac{y c_{t-1}}{a_{t-1} l s_{t}} .
$$

It measures the spread between the number of existing work-stations and the number necessary to reach full employment. With the above calibration, there is initially no positive capital gap.

\footnotetext{
${ }^{12}$ This comparison between a negative shock on the productivity of the factors (in terms of added value) and an oil shock is meaningful if for instance energy is a complementary factor to capital and labour in the production function. This sufficient (but not necessary) assumption seems realistic.
} 

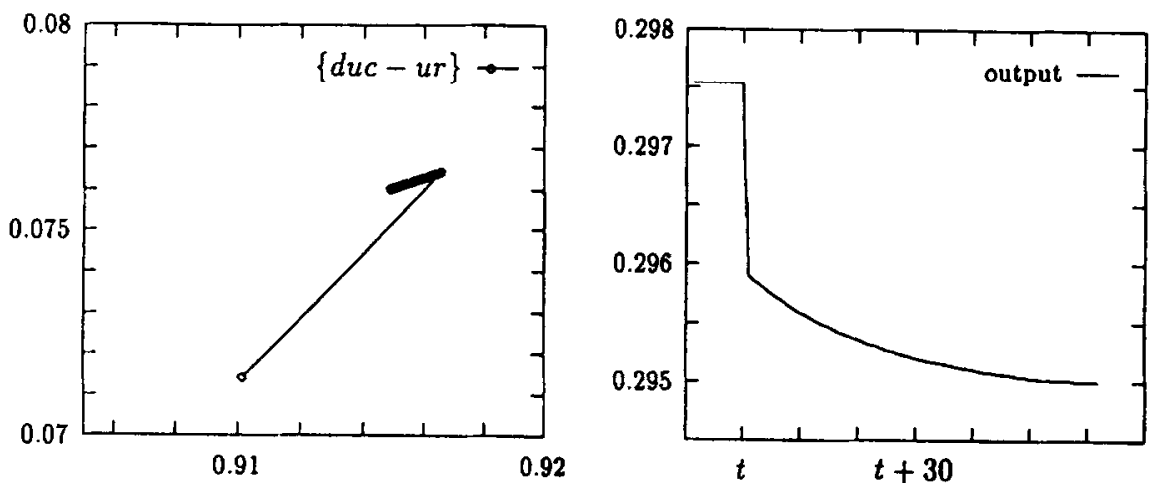

Fig. 2. Increase in real interest rate.

\subsubsection{Increase in real interest rate}

The annual interest rate is raised from 0.08 to 0.10 . Simulation results are presented in Fig. 2. The main effect is linked to the consecutive loss of profitability for firms: the higher cost of capital reduces the optimal level of productive capacities. This effect on productive equipments is strengthened by the fact that the optimal rate of capacity utilisation has risen too. Indeed, the firms revise their trade-off between their interest to accumulate excessive capacities because of the uncertainty on demand and the cost of this investment. All this means destructions of work-stations and thus a higher equilibrium unemployment rate. The positive effect of the capital-labour substitution on employment is much too weak to overcome the negative impact on labour demand. Thus higher real interest rates mean higher unemployment and higher degree of capacity utilisation. $^{13}$

\subsubsection{Negative productivity change}

We simulate here an unexpected change in the total factor productivity $\tau$ from 7.75 to $7.25 .{ }^{14}$ Results are presented in Fig. 3. This unexpected change causes a rise in marginal unit labour cost in response to which firms rise their prices. This leads to a fall in real demand explaining the drop in $d u c$ during the first

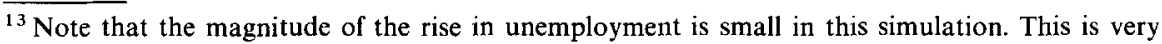
dependent on the chosen calibration. For instance, a lower $\varepsilon$ will lead to a much larger effect of interest rates on the endogenous variables.

${ }^{14}$ This change is close to a permanent change in the deterministic part of the Solow residual, this residual being the main driving force of a large class of real business cycle models.
} 

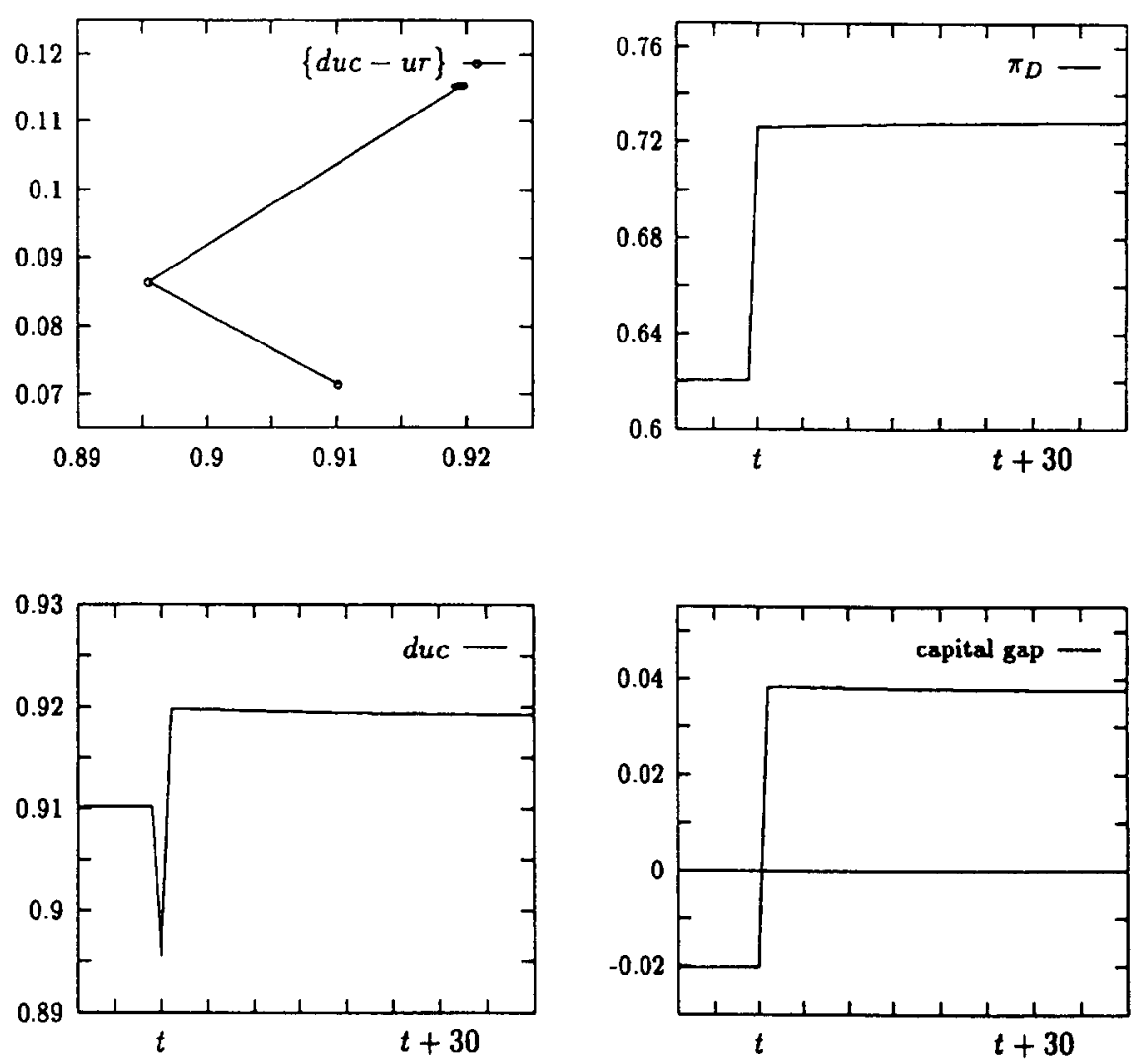

Fig. 3. Negative productivity change.

period following the shock. Simultaneously, $\pi_{D}$ rises explaining a lower mark-up over marginal costs. This rise in $\pi_{D}$ implies also an increase in the labour share in added-value. During the following periods, the fall in productivity of factors and the loss in unitary operating surplus depress investment. This destruction of productive capacities explains the concomitant rise in $u r$ and duc (and prices). The reason why the steady value of $d u c$ is higher than before the shock is of the same type as the one invoked for the previous simulation.

On top of these effects on $u r$ and $d u c$, it is worth noting that this productivity shock causes a set of stylised facts observed after the oil shocks:

1. a higher proportion of firms reporting to face demand shortages (without implying by itself a Keynesian problem);

2. higher prices but lower mark-up;

3. the appearance of a capital gap. 


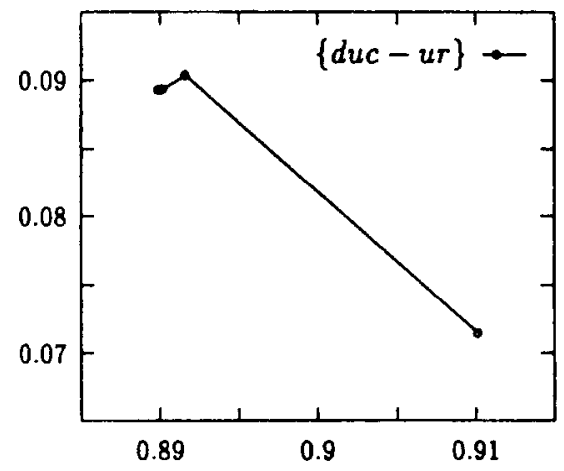

Fig. 4. Increase in uncertainty.

\subsubsection{Increase in uncertainty and mismatch}

One of the main interest of the QRM framework is to link mismatch unemployment to microeconomic uncertainty and labour market segmentation. The main consequence of a larger uncertainty is a lower expected output at given productive capacity. Firms are thus led to reduce the optimal level of their equipment. The macroeconomic impact of these micro-perturbations is a rise in $u r$. This increase in $u r$ can be interpreted as a rise in structural unemployment. In the space unemployment-vacancies, it can be shown the corresponding Beveridge curve shifts outward. In our case, this shift is directly linked to an optimal response to increasing uncertainty.

The increased uncertainty (or mismatch) reduces the optimal $d u c$ for firms. The small effect of capital labour substitution which appears in Fig. 4 is linked to the fall in the optimal rate of capacity utilisation as it raises the cost of equipment (one unit of capital good costs $p^{i}(r+\delta)$ per period. As this unit is used at a rate $d u c$, its cost is multiplied by one over $d u c$ ).

\subsubsection{New technology}

Finally, we simulate here a technological change augmenting the productivity of labour. Eq. (1) should be rewritten as

$$
\Delta y c_{t}^{c}=\left[d\left(\alpha \Delta n_{t}^{h}\right)^{(\sigma-1) / \sigma}+(1-d)\left(i_{t}^{h}\right)^{(\sigma-1) / \sigma}\right]^{\sigma /(\sigma-1)}
$$

where $\alpha$ becomes larger than one (1.015) in the new technology. ${ }^{15}$ Given the putty-clay nature of the production function, our model seems suitable to

\footnotetext{
${ }^{15}$ The Euler equations have of course been modified accordingly but these modifications are not reported here.
} 

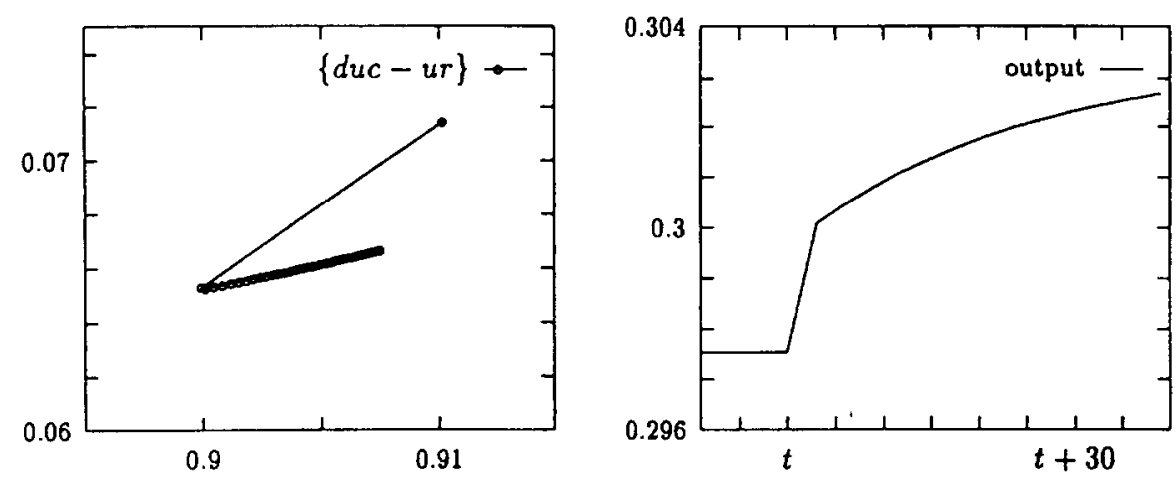

Fig. 5. New technology.

simulate such a technical progress convincingly since it can only be incorporated in the firm's equipment through new investments.

The impact on the economic activity is immediately positive: investments in most productive equipments are indeed stimulated by the incentive to reduce rapidly the cost of labour. Prices decrease progressively (but the mark-up rate rises as $\pi_{D}$ diminishes). As far as the evolution of the unemployment rate is concerned, the initial investment wave creates new work-stations (see Fig. 5). When the investment rate comes back to the depreciation rate, the negative impact of the labour-capital substitution offsets progressively the initial gain in employment. The long-term effect on unemployment remains however slightly negative.

\section{Monte Carlo experiments}

Since the productivity parameter $\tau$ appeared to play an interesting role in our framework we have investigated the implications of a stochastic behaviour of this parameter on the endogenous variables. For this purpose we specify an autoregressive process of order one for the total factor productivity $\tau$ in the spirit of RBC models. (with an autoregressive coefficient of 0.85 ). For each replication (here out of 60 ), the productivity shock process is initialized with the value found at the previous 'period' and a new perturbation is drawn. Following Boucekkine (1993), for each replication, we compute the deterministic solution path $^{16}$ and extract the variables at date $t=1$ in order to form pseudo time series

\footnotetext{
${ }^{16}$ We set all future shocks to 0 which means that we approximate the rational expectations by perfect expectations. This approximation is the main drawback of Boucekkine's method but it may be valid provided that the variance of the pertubation is not too large.
} 
of the endogenous variables. Numerous analyses can be carried out but we want to focus on three points:

1. As in neo-classical models, a technological shock does not succeed neither in explaining the cyclical behaviour of prices (the instantaneous correlation between the pseudo time series of output and prices is -1) nor in reproducing the low correlation between output and labour productivity.

2. The instantaneous correlation between $u r$ and $d u c$ is 0.54 which is much higher than the observed correlation of 0.04 (computed with the series of Fig. 1). This means that productivity shocks alone tend to generate a too positive correlation between $u r$ and duc. The relative volatility of the pseudo time series of $u r$ with respect to $d u c$ is 2.5 while it is near 1 using actual data.

3. The model generates little persistence in addition to the one of the shock itself. Augmented Dickey-Fuller tests have been computed and indicate that our pseudo time series are stationary and that the autoregressive coefficients are below 0.9 ( 0.85 for the shock, 0.87 for output, 0.5 for $d u c$ and 0.89 for $u r$ ).

To complete this very rapid presentation of the potential interest of our model in a stochastic environment, we also analyse the behaviour of endogenous variables when $\rho$ is stochastic (without random productivity). An AR(1) process for $\rho$ is specified with the same autoregressive coefficient of 0.85 . The simulations show that this source of uncertainty reproduces the low correlation between output and labour productivity $(0.08)$, and the unitary relative volatility of $u r$ to $d u c$. Unfortunately, the contemporaneous correlation between $u r$ and $d u c$ is -1 .

\section{Open problems}

In this section, we clarify and motivate some characteristics of the model (partial equilibrium, efficient bargaining), and we assess the relevance of future research for improving and/or testing our framework.

\subsection{The role of demand and the general equilibrium}

As the optimal formation of prices and wages in the model is only responsible for real rigidities ${ }^{17}$, unemployment in our model can be assimilated to an equilibrium unemployment rate à la Layard et al. (1991) in an intertemporal context. The $u r$ and $d u c$ dynamics do thus rely on real phenomena only. This allows us to point out the ambiguity of some indicators given in business surveys. In particular, a higher proportion of firms reporting demand shortages

\footnotetext{
${ }^{17}$ Introducing staggered contract in a dynamic wage bargaining framework as in Manning (1989) would open the door to nominal rigidities.
} 
do not reflect in itself a more Keynesian behaviour of the economy. As far as this last point is concerned, a more detailed discussion on the respective role of nominal and real rigidities in a QRM model with aggregation can be found in Sneessens (1992).

Since the labour supply is exogenous and the price elasticity of demand is constant, the consequence of a 'real model' of unemployment is that aggregate demand does not affect output. If $\bar{C}$ increases (through for instance a rise in the propensity to consume), the general level of prices will adjust in order to keep $\bar{C} / p$ unchanged. The fact that aggregate demand is 'neutral' limits the interest of completing the model by describing the optimal consumption path and by adding the national account identity which guarantees that aggregate demand is decomposed in aggregate consumption and aggregate investment. However, a general equilibrium perspective should be useful to endogenise the interest rate. This generalisation remains a priority for our future work.

\subsection{Efficient bargaining}

Efficient bargaining models in a static framework are often criticised as being time inconsistent. This time inconsistency is due to the fact that the firm has always an incentive to deviate from the contractual employment level and to return ${ }^{18}$ on its labour demand curve once the wage has been fixed. When dynamic aspects are introduced, by considering for instance an infinitely repeated game, an opportunity exists for the agents to build a long-term relationship that may lead to an efficient outcome. The conditions under which the efficient outcome emerges in a repeated bargaining game are derived in simple models by Espinoza and Rhee (1989) and Strand (1989). Basically, if the discount rates of the agents are high enough, the future consequences of any deviation from the contract (punishment or return to the non-cooperative outcome) have more weight than the instantaneous benefit from deviating from co-operation. Therefore, in that case, the cooperative outcome is time-consistent.

The mechanism through which such a cooperative outcome could emerge is detailed in Eberwein and Kollintzas (1995). Their argument applied to our framework is the following: at the cooperative solution, the union sets a wage along the contract curve. It does so, however, expecting the firm to cooperate and set its price and investment compatible with the expected employment level along the contract curve. If the firm cooperates by setting a low enough price and a high enough investment, the union continues to cooperate in the future. If the firm does not cooperate, the union starts a punishment strategy by moving

\footnotetext{
${ }^{18}$ In the absence of a legal enforcement procedure.
} 
towards the non-cooperative equilibrium as in Espinoza and Rhee (1989). If the agents give enough weight to the future (i.e. if their discount factor is high enough) it is optimal for them to cooperate.

One drawback of our wage formation process is the constancy of the real wage. This result comes from the fact that the bargaining objective function is linear in employment but concave in the real wage. A way to have a richer wage formation mechanism is to introduce union's habit formation processes, as it is proposed by de la Croix et al. (1993).

\subsection{Empirical relevance}

The relevance of the shocks we have explored should be investigated further by the mean of an econometric and/or simulation-based study. It is, however, useful to compare our result with some recent empirical researches.

As far as the productivity shock is concerned, Eberwein and Kollintzas (1995) propose a $\mathrm{RBC}$-like stochastic dynamic bargaining model describing the reaction of firms and unions in the face of aggregate uncertainty on productivity. It appears first that the efficient contract dominates the non-cooperative behaviour and second that the model may account for a low variability of wages with respect to employment. This implies that unemployment could be significantly affected by these productivity shocks.

Our simulation concerning the role of interest rates could also lead to some empirical questions. The idea that high real interest rates are responsible for the unemployment in Europe in the 1980s has mainly been brought by Fitoussi and Phelps (1988). Their view is based on 'customer-market' models: in brief, if the interest rate increases, the firms put more weight on today's profits and are more ready to loose some customers through a high price policy. This leads to increases in mark-up rates and in unemployment, Our model based on capital shortages leads to the same kind of effect of interest rate on employment as the customer market story, but through a different channel. The empirical relation between unemployment and interest rates is analysed in de la Croix and Lubrano (1995). They show that interest rates and unemployment rates are cointegrated in Belgium, France, Denmark and Germany provided that a breaking point is allowed. The real interest rate is shown to be weakly exogenous, providing support to the hypothesis of a long-run causation of interest rates on unemployment after 1974. The breaking point could be interpreted in the framework of this paper as a change in the productivity parameter.

The policy implications of our framework are also worth noting. If it appears that interest rates are exogenous as a consequence of the particular institutional set-up in the EEC, a high $d u c$ and a high ur indicate that one would gain in lowering the real interest rate. This contradicts the view of the German Bundesbank according to which a high $d u c$ is necessarily an indication that 
the interest rate should be kept at a high level to refrain the expansion of demand.

\section{Conclusion}

Our analysis aims at understanding some aspects of the dynamics of unemployment and the rate of utilisation of productive equipment by taking explicitly into account both the quantity constraints suggested by these two variables and the heterogeneity of microeconomic situations in a model with rational expectations. As the presence of unemployment in the short and the long run relies essentially on non-competitive wage and price formation, the model remains rather elementary. However, it characterises interestingly the evolution of $u r$ and $d u c$ in the face of unexpected changes in the economic environment similar to those experienced by European economies. In particular, drops in total factor productivity increase both unemployment and the degree of capacity utilisation in the long run. It is also worth noting that the productivity shock allows to understand a set of stylised facts observed after the oil shocks: a higher proportion of firms reporting to face demand shortages (without implying by itself a Keynesian problem); higher prices but lower mark-up; the appearance of a capital gap. The model is also suited to study changes in firm-level uncertainty and their effect on structural unemployment. Of course, our framework provides no answer to the question of knowing why unemployment remained so high once these perturbations vanished. The introduction of mechanisms accounting for persistence would certainly be a priority for future works.

\section{Acknowledgment}

This paper was written while the first author was research fellow at the university of Limburg (Department of Quantitative Economics) and the second author was a visitor at CEPREMAP. We thank Jean-Pascal Benassy for very stimulating discussions. We would also like to thank Pierre Malgrange for his comments on an earlier draft. Jean-François Fagnart gratefully acknowledges the financial support of the 'Projet d'action concertée' 93/98-162 of the ministry of scientific research of the Belgian French Speaking Community.

\section{References}

Arnsperger, C. and D. de la Croix, 1993, Bargaining and equilibrium unemployment: Narrowing the gap between New Keynesian and disequilibrium theories, European Journal of Political Economy 9, 163-190.

Bean, C., 1989, Capital shortages and persistent unemployment, Economic Policy, 12-53. 
Blanchard, O. and C. Kahn, 1980, The solution of linear difference models under rational expectations, Econometrica 48, 1305-1311.

Boucekkine, R., 1993, A Monte-Carlo experimentation for large-scale forward-looking economic models, in: A. Hoden, ed., Proceedings on nonlinear science (Wiley, New York).

Boucekkine, R., 1995, An alternative methodology for solving non-linear forward-looking models, forthcoming in The Journal of Economic Dynamics and Control.

Boucekkine, R. and C. Le Van, 1993, How to detect finite difference linear saddlepoint models using relaxion algorithms, Mimeo. (CEPREMAP. Paris).

Burda, M., 1988, Is there a capital shortage in Europe, Weltwirtschaftliches Archiv, 38-57.

Card, D., 1986, Efficient contracts with costly adjustment: Short-run employment determination for airline mechanics, American Economic Review 76, 1045-1071.

Danthine, J.-P. and J.B. Donaldson, 1989, Efficiency wages and the businees cycle puzzle, European Economic Review 34, 1275-1302.

de la Croix, D., 1992, Union-firm bargaining, investment and equilibrium unemployment, Research Memorandum 92-048 (Limburg University, Maastricht).

de la Croix, D. and M. Lubrano, 1995, Are real interest rates responsible for unemployment in the eighties? A Bayesian analysis of cointegrated relationships with a regime shift, in: T. Fomby, eds., Advances in econometrics: Bayesian methods applied to time series (JAI Press, Greenwich, CT) forthcoming.

de la Croix, D., F. Palm and G. Pfann, 1993, A dynamic contracting model for wages and employment, Mimeo.

Drèze, J. and C. Bean, 1990, European unemployment: Lessons from a multi-country econometric exercise, in: J. Drèze et al., Europe's unemployment problem (MIT Press, Cambridge, MA).

Eberwein, C. and T. Kollintzas, 1995, A dynamic bargaining model in a unionized firm with irreversible investment, forthcoming in Annales d'Economie et de Statistique.

Entorf, H., H. Konig and W. Pohlmeier, 1992, Labor utilization and nonwage labour costs in a disequilibrium macro framework, Scandinavian Journal of Economics 94, 71-83.

Espinoza, P. and C. Rhee, 1989, Efficient wage bargaining as a repeated game, Quarterly Journal of Economics 104, 565-588.

Fitoussi, J.-P. and E. Phelps, 1988, The slump in Europe (Basil Blackwell, Oxford).

Laffargue, J.P., 1990, Résolution d'un modèle macroéconomique à anticipations rationnelles, Annales d'Economie et de Statistisque 17, 97-119.

Lambert, J.-P., 1988, Disequilibrium macroeconomic models (Cambridge University Press, Cambridge, MA)

Lambert, J.-P. and B. Mulkay, 1987, Investment in a disequilibrium context or does profitability matter?, Discussion paper 8703 (CORE, Louvain-la-Neuve).

Layard, Nickell and R. Jackman, 1991, Unemployment: Macroeconomic performance and the labour market (Oxford University Press, Oxford).

Licandro, O., 1992, Investment dynamics and capacity utilization in monopolistic competition, Annales d'Economie et de Statistique 27, 91-113.

Lockwood, B. and A. Manning, 1989, Dynamic wage-employment bargaining with employment adjustment costs, Economic Journal 99, 1143-1158.

Lucas, R. and M. Woodford, 1993, Real effects of monetary shocks in an economy with sequential purchases, Working paper (NBER, Cambridge, MA).

Manning, A., 1989, Dynamic wage bargaining and staggered contracts, Mimeo. (London School of Economics, London).

Osano, H. and T. Inoue, 1991, Testing between competing models of real business cycles, International Economic Revicw 32, 669-688.

Sneessens, H.R., 1983, Aggregation in quantity rationing models, Mimeo. (Département des Sciences Economiques, Université Catholique de Louvain, Louvain-la-Neuve). 
Sneessens, H., 1987, Investment and the inflation-unemployment trade off in a macroeconomic rationing model with monopolistic competition, European Economic Review 31, 781-815.

Sneessens, H., 1992, Contraintes de débouchés, capacités de production et chômage dans un modèle macroéconomique avec concurrence imparfaite, L'Actualité Economique 68, 140-174.

Strand, J., 1989, Monopoly union versus efficient bargaining: A repeated game approach, European Journal of Political Economy 5, 473-486. 